\title{
Analysis of the Countermeasures of the Development of Cultural Creative Industry in Western Jilin
}

\author{
Tian Liyuan ${ }^{1, a}$ * \\ ${ }^{1}$ Ideological and Political Theory Teaching Department, Baicheng Normal University, Baicheng, Jilin, \\ 137000, China \\ aemail: tianliyuanwang@163.com
}

Keywords: Western Jilin, cultural creative industry, countermeasure

\begin{abstract}
The continuous and rapid development of the cultural creative industry in western Jilin, has become a an important choice to speed up the transformation of the pattern and to improve the quality and efficiency of economic development in western Jilin, The government should promote cultural innovation, accelerate the development of industry by cultivating the innovative spirit, improving the industry development planning, and the development of industrial cluster and actively cultivating regional characteristic culture brand, by optimizing the measures of environment to dig depth of local culture and implement the cultural creativity.
\end{abstract}

\section{Introduction}

Western Jilin Situated in the southwest of Songnen plain. It has a vast territory and abundant resource and like a dustpan shape because its high in three sides west, east, and northern, low in center. The area includes 10 counties such as Taonan, Daan, Zhenlai and so on, they governed by two cities Baicheng and Songyuan. In recent years, with the continuous deepening of the reform in cultural system of Jilin province, Western Jilin's cultural creative industry has a rapid development, it represented by the emerging of the industry of radio, television, film, animation, games and so on. The cultural creative industry has become the important option for the transformation of the pattern of economic development and the optimization of industrial structure in the west of China. But it also faces many problems due to lacking of leading enterprises, resource integration, top talent shortage, poor investment environment, and the nonstandard market management. Such problems lead to slow innovative technology, product of low technology content and poor competition ability. So the development scale and level of the cultural creative industry cannot meet the new development requirements. So, how to solve these problems, to achieve Western Jilin's leap development of the cultural creative industry, has become an important task to transform the pattern of economic development and to optimize industrial structure.

\section{The Development Of Cultural Creative Industry In Western Jilin}

Cultural creative industry in Jilin province started late, which emerged in recent years and presents good development momentum today. Their creative industry office Founded in October 2006, formal creative industry is put forward [1]. Jilin Provincial government pay high attention to and strongly support the development of cultural creative industry, has launched a series of supporting policies and developed 'the accelerating plan of cultural industry in Jilin province (2011-2015) ', it is the symbol the cultural creative industry in Jilin province entered a new phase. In this context, Western Jilin's cultural creative industry also developed rapidly, and has become an important choice to adjust the industrial structure, to transform the mode and to improve the quality and efficiency of economic development.

In recent years, Baicheng's cultural creative industry is in constantly developing, its scale of the industry is expanding, has gradually formed the cultural industry group including the cultural entertainment, the network services and printing, which has become an important part of market economic system. The cultural Industry Park was founded in 2011, through the government 
guidance a broader measure of 'social financing', highlight cultural characteristic of industry, the Park has received some Companies with development potential and strong cultural industry enterprises more than 350 households by 2014, that Expected turnover is about RMB 300 million per year. It is expected to be built a large cultural industrial park including ten 10 kinds of key cultural industry such as radio, film and television, performing arts entertainment, press and publishing, entertainment, Game and Animation, digital transmission, network services and so on. This can promote the cultural industry to be the main industry for economic development in Baicheng. At present, the city's cultural management place, a total of 1058 cultural companies, the practitioners could exceed 20000, and the company more than 2000 ten thousand yuan. The annual tax is 150 million Yuan RMB.

In recent years, the Songyuan municipal government pay high attention to the development of cultural industry, has introduced some files, such as the opinions on the promotion of cultural industry prosperity and development. They have clear regulation for layout of cultural industry, the focus on supporting and the promotion policies, it has attracted much attention to cultural industry and a growing number of investors to this cause. Songyuan has four reengineering projects which actively promoted some major projects of cultural, built brand characteristics foster leading cultural enterprises and developed cultural industries. Songyuan's target is "transformation development, rich the city, building happy Songyuan ", these policies unlock the development potential and promote the deep integration between tourism industry and cultural industries in this city. By 2013, Songyuan already has attracted 11 medium-size cultural enterprises and 122 small-scale cultural enterprises, And 11 business enterprises operating wholesale-retail sales cultural articles .The added value of cultural industry totaled 2.32 billion yuan, make up of a 1.5\% of the city's GDP[2].

\section{The Problems In The Development Of Western Jilin's Cultural Creativity Industries}

The Poor Awareness And Backward Creative Consciousness. First, the insufficient understanding is not in place about the development of cultural creativity industry.

Which highlights that lacking of understanding the important role that the cultural creative industry play in the promotion economic and social development, without fully understanding about the great potential of development of the cultural creative industry and cannot think of the development of cultural creative industry as an important pillar industry in Industrial Structure Adjustment.

Second, the backward creative consciousness, the lack of motivity for innovation. In recent years, Western Jilin's cultural creative industry has a rapid development; the main performance is that rapid progress in radio, film and television, Game and Animation. But, its low scientific and technical content and weak competitive ability for its low technology and weak innovation ability. At the same time, their products are similar because no innovation, they have no their own brand and characteristic products in their creative cultural industry, so they failed to form their own style and features in the aspect of construction of the culture creative industry gathering.

The System Defect And The Inadequate Capacity Of Self-Development. First, the system of industrial development lack in energy. At present, the development of western Jilin's culture creative industry mainly rely on government investment and subsidy system, this kind of mode resulted in the lack of development driving force. There is rich cultural resources historical and cultural relics, natural geography, human geography, landscape, etc., in western Jilin; it provides rich contents for the development of cultural industry. It need two key factor to transform the rich cultural resources into social wealth, which are the capital market and the Information Technology just like two-wheel, But, Western Jilin is not mature in these two aspects, so can not to make use of the resources advantage.

Second, the lagged industrial development planning, the inadequate capacity of self-development. Scientific planning is a guarantee of cultivating creative industry. Jilin western region the development of cultural creative industry is lack of long-term planning go through scientific argumentation, the industry layout lack of rationality.

The Shortage Of Culture Talents And The Unbalanced Talent Structure. At present, there is 
talent shortage in Western Jilin's cultural creative industry, they lack management personnel, professional and technical personnel and interdisciplinary talents, and, the whole quality of the cultural creative industry practitioners waits for improvement, and the quantity, the quality and the structure of talents cannot fulfill the needs the development of the cultural creative industry at present. At the same time, the talent structure is unbalanced, there are problem on high-level personnel distribution especially in higher-value-added businesses such as the electronic games, animation production, network services, software development, etc., talent shortage is the main problem. In addition, lack of interdisciplinary talents that good at marketing and management. the existing mechanisms, working conditions and the salary is that of The restriction of, talents exploitation degree and other reasons, caused the existing talent is difficult to give full play to the role, a large number of brain drain, the backbone of middle-aged and young to absorb more high-end talent.

The Negative Investment Environment And The Single Financing Channels. One of the main problems with western Jilin's culture creative industry is that their financing channel is not smooth. The first problem is in direct financing, because most of the cultural creative company is too small, low of popularity and low credit rating to meet the qualifications and conditions to access to market capital.

The second problem is the in indirect financing. Despite some financial institutions face the financing of the small and medium-sized enterprises, but they prefer to load large enterprises for their large loan. So that commercial banks for-profit lack of motivation to loan for small and medium enterprises.

The Cultural Enterprises Are Small And Lack Of Synergies. At present, the leading culture enterprise in western Jilin are facing short of earning ability, no exemplary role, small-scale and weak industry basis, so they have no economies of scale and aggregation. The backbone Cultural enterprise's strength is limited, their investment focus primarily on the construction of cultural scenic area and the exploitation of the culture resources. But the disadvantages of these kinds of Business Model is that the industry chain is shorter, the capacity of radiation is weaker. In addition, the single development mode of cultural industry, mean that they cannot form cross-sectoral and inter-regional integrated economic entity. These private enterprises are low level of technology and small size. The cultural industry park's development lies in the unclear orientation and coessential change serious and the construction of cultural market should be strengthened. The investment and financing system are not perfect and the policy effects of the fiscal and taxation is not effective enough.

\section{The Suggestions And Countermeasures To The Development Of Cultural Creativity Industry In Western Jilin}

Heighten Ideological Understanding And Establish New Idea Of The Industry Development. Local leaders at all levels must genuinely understand the significance of the development of cultural creative industry from the height of building an innovative country and from the height of regional development during the "twelfth five-year" and from the general situation. So the new idea of industry development should be based on the understanding of the regional advantage and the practical conditions. Unfortunately, some art troupes in Western Jilin have no the capacities of its existence and development, they are still mostly dependent on government funding. What is called "reform" was in fact a signboard of market, not establish modern enterprise system. The main reasons of the lagging reform of some cultural enterprises is due to the conservatism and backward method on industry development, they lack of the foresight and pioneering spirit and the innovative and effective way in the marketization reform.

Clarify The Trend Of Cultural Industrial Development, Pay More Attention To The Cluster Development. Local leaders at all levels should conduct deep analysis and research of the environment for the development of cultural industry. And further understand the opportunities and challenges what the industry facing, so that to formulate the development plan which accords with of local economic development and cultural traditions, and clarify the trend of cultural industrial 
development. At the same time, to guide the industry cluster development. The Construction of creative industry park is one of the important ways of cultural creative industry cluster. Western Jilin should strive to develop the wetland science and approach it as the key project, and approach the winter fishing, the Mongolian folk customs cultures, the grassland tourism, and the birding in wetlands as the characteristic project, which have regional characteristic of Northeast culture. And to aggressively build the agglomeration of creative cultural industry which are ecological landscape area of wetland and prairies and the folk cultures represented by the Chagan Lake, Momoge nature reserve, Qian'an mud forest[3].

Make Relevant Policies And Perfect The Systems Of Service For Industry Development. In the planning policy, incorporate the infrastructure project of industrial park into the construction plan of key infrastructure in "twelfth five-year", which the government should make a priority in planning and land for the cultural creative industry. In the fiscal and taxation policy, I suggest to set up a fund set up special fund cultural creative industry to support industry development by rewarding, interest subsidy and subsidy. In the aspect of investment and financing policy, to smooth the channels by which the venture capital and social capital can inflow into the creative industry, and, To support and guide the credit guarantee institutions provide financing guarantee service for small and medium-sized cultural creative enterprises. In the aspect of the improvement in marketability of cultural creative products and property rights, to further improve the copyright laws and regulations to protect the intellectual property rights of creative product, to regulate the market and promote marketization and maturity of creative industries. In the talent policy, to reform and improve the creative talent introduction, cultivation, use, and incentive policies, to create a good environment for the emerging of outstanding professionals of creative industries.

Integrate Cultural Resources And Cultivate The Brand Of Regional Culture .The local government and business organizations should know to establish brand awareness, pay more attention to the comparative advantage by the deep excavation of local historical cultural resources in order to cultivate famous brand of regional culture. They should actively promote cultural industry development base construction, accelerate the development of cultural Creative Park and advance the development of the cultural industry projects and the aggregation of cultural industry enterprises by resource integration, supporting leading enterprises and elongating the industrial chain. In this way, the resources advantage can be transform into industrial advantage and competitive advantage, by which, the industry scale, production intensification, and specialization level of the cultural creative industry can be promoted. They should integrate Local culture tourism resources and drive cultural creative industry to fuse with technology industry, promote the development the cultural creative industry through the protection and exploration of local cultural relic, the arrangement and exploration of the Intangible Cultural Heritage.

Deepen The Structural Reform And Optimize The Development Environment Of Creative Industry. Promoting the reform of cultural system, the starting point is that coordinated development in cultural undertakings and culture creative industry, the technology innovation and cultural creativity should be regarded as entry points. On the basis of the development of non-profit pubic causes, they should vigorously support some creative industries such as the animation industry, radio, film and television, arts and crafts, software design, advertising design, fashion design, performance art, and publishing, deepen the reform of the investment system of cultural industry. The government should improve and implement the investment policy of culture industry and mobilizes social forces to participant the development strategy of cultural industry, establish multi-channel of finance, and, actively promote those for-profit cultural enterprises to transform from public undertakings, at the same time, implement a variety of ownership composition and mobilize social forces to participant the development strategy of cultural industry, and, actively conduct exchanges and cooperation to to develop and innovate the export-oriented cultural creative industry, drive the creative cultural industry "going out" through the creative cultural products "going out", and strongly promote more featured brands "going out", to increase market share and brand awareness of the cultural creative industries at home and abroad. 


\section{References}

[1] Meng Tao. Research on cultural creative industry policy of Jilin province [D]. Jilin University, 2010.

[2] Yang Huiguang. Cai Weixiu. Songyuan vigorously promotes the development of cultural industry[R]. Jilin Daily, 2013-11-27.

[3] Zhang Shuxi. The study on efficiency of china's cultural creative industry and its influencing factor [D]. Anhui Finance and Economics University, 2013. 